\title{
Empowering Internet of Things (IoT) through Big Data
}

\author{
Bayu Prabowo Sutjiatmo, Alfian Erwinsyah, E. Laxmi Lydia, K. Shankar, Phong Thanh Nguyen, \\ Wahidah Hashim, Andino Maseleno
}

\begin{abstract}
The coming of new advancements, devices and union of remote correspondence, computerized hardware, and miniaturized scale electro-mechanical frameworks (MEMS) advances have brought about the development of Internet of Things (IoT) which thusly delivers an enormous measure of information. IoT helps in diminishing expenses and expanding income, however at the expense of creating tremendous information. The organization of colossal data in an always stretching out framework offers rise to non-irrelevant worries as for data gathering capability, data planning, assessment, and security. This paper describe the benefits of big data in IOT. And also describe architecture and various applications of IOT.
\end{abstract}

Keywords : Internet of things, big data, analytics, distributed computing, smart city.

\section{INTRODUCTION}

Because of the Internet and accessibility of system assets anybody can accumulate the required data effectively and its utilization is changing ceaselessly with every single second. The coming of new advancements, devices and union of remote correspondence, computerized hardware, and miniaturized scale electro-mechanical frameworks (MEMS) advances have brought about the development of Internet of Things (IoT) which thusly delivers an enormous measure of information. IoT frames a system of interconnected devices, for example, PCs, workstations, WiFi, sensor empowered deices and family unit machines which delivers a major information and it is normal the this enormous information will increment from 22.9 billion out of 2016 to 50 billion by 2020 and will keep on expanding. IoT helps in diminishing expenses and expanding income, however at the expense of creating tremendous information. So as to get profits by IoT, associations should plan a stage that can procedure, oversee and dissect tremendous measure of information in adaptable and financially savvy way. Enormous information gives such

Revised Manuscript Received on July 22, 2019.

* Correspondence Author

Bayu Prabowo Sutjiatmo, Politeknik APP Jakarta, Indonesia. E-mail: bayu@kemenperin.go.id

Alfian Erwinsyah, Faculty of Tarbiyah and Teacher Training IAIN Sultan Amai Gorontalo, Indonesia

E. Laxmi Lydia, Professor, Vignan's Institute of Information Technology(A), Department of Computer Science and Engineering, Visakhapatnam, Andhra Pradesh, India. E-mail: elaxmi2002@yahoo.com

K. Shankar, Department of Computer Applications, Alagappa University, Karaikudi, India. Email: shankarcrypto@gmail.com

Phong Thanh Nguyen*, Department of Project Management, Ho Chi Minh City Open University, Vietnam. E-mail: phong.nt @ ou.edu.vn

Wahidah Hashim, Institute of Informatics and Computing Energy, Universiti Tenaga Nasional, Malaysia.

Andino Maseleno, Institute of Informatics and Computing Energy, Universiti Tenaga Nasional, Malaysia. a stage that can procedure voluminous and complex information sources, yet in addition helps in quickening the information mix.

\section{BIG DATA}

Immense Data is a social affair of device datasets that can't be readied using standard figuring systems. It escapes to enlightening lists or mixes of educational accumulations whose gauge (volume), unpredictability (variability), free data (veracity) and pace of advancement (speed) make them difficult to be gotten, directed, arranged or inspected by normal developments and instruments, for instance, social databases. To choose if a particular instructive record size is seen as a noteworthy data isn't unflinchingly described as it continues changing after some time. Information is distributed by various sources and after this it connects with the system at various rates. The range of educational accumulations is from terabytes to various petabytes, and is rapidly rushing toward exabytes.

\section{BENEFITS OF BIG DATA PROCESSING}

As we know big data processing has many advantages like:

- Outside information can be used by organization according to choices Communal information can be achieves by various web crawlers and locales like facebook, twitter are authorizing associations to regulate their professional approaches.

\section{- Enhanced customer management}

Regular customer analysis systems are getting replaced by new structures arranged with Big Data developments. In these new structures, Big Data and basic language taking care of headways are being used to scrutinize and survey client responses.

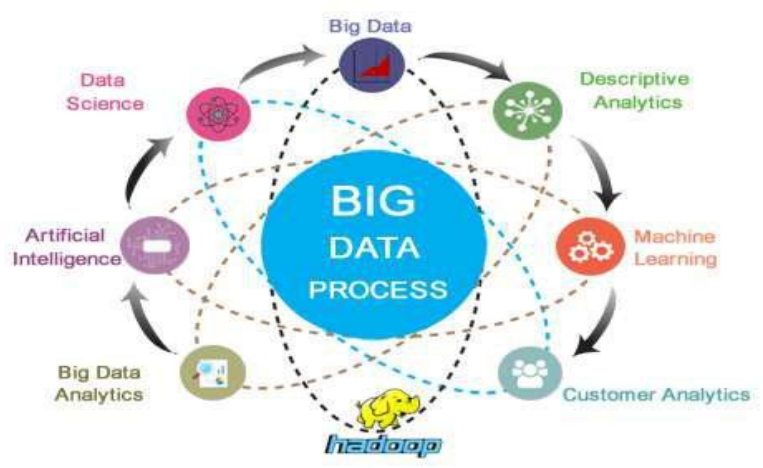

Fig1: Big Data Processing 
Early distinguishing proof of hazard to the item/administrations, assuming any Better operational productivity.

Huge Data developments can be used for making an arranging zone or landing zone for new data before recognizing what data should be moved to the data stockroom. Also, such incorporation of Big Data advances and information stockroom encourages an association to offload inconsistently got to information.

\section{INTERNET OF THINGS}

The advances in IT cause it conceivable to structure a shrewd society in which devices to can discuss effectively with each other when associated with the Internet. Figure exhibits that in an IoT organize, anything's will prepared to pass on to the web at whatever point from wherever and offer organizations to anyone. Its application, for instance, sharp vehicle and the quick home, can give various organizations, for instance, alerts, security, imperativeness saving, computerization, correspondence, PCs and delight.

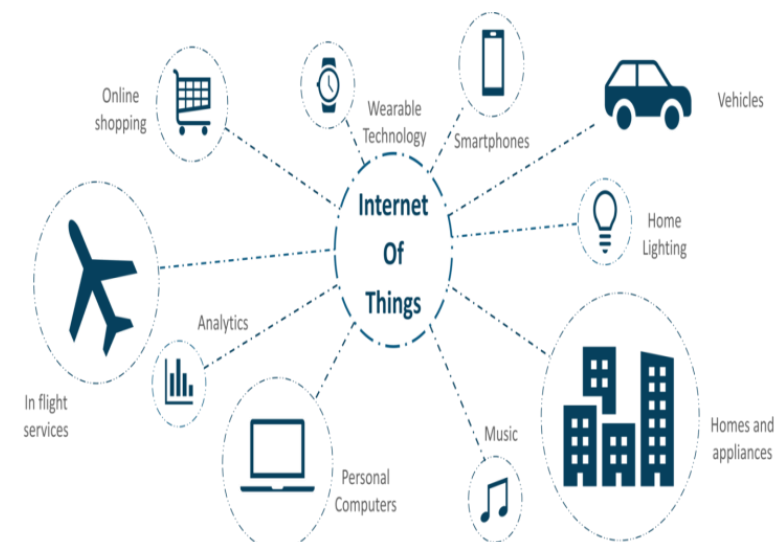

Figure 2: Internet of Things

Exactly when affiliations are holding onto the data for assessment reason, IoT is going about as an imperative hotspot for that data, and this is the place the activity of colossal data in IoT comes into the picture. Tremendous data assessment is creating as a crucial perspective for separating IoT delivered data from "related devices" which ventures up to the plate and improve fundamental initiative.

The activity of huge data in IoT is to process a great deal of data reliably and securing them using unmistakable limit headways.

IoT tremendous data getting ready seeks after four continuous advances -

1. A huge proportion of unstructured data is created by IoT contraptions which are assembled in the enormous data system. This IoT delivered colossal data for the most part depends upon their $3 \mathrm{~V}$ factors that are volume, speed, and arrangement.

2. In the tremendous data structure which is basically a typical passed on database, the immense proportion of data is secured in enormous data reports.

3. Analyzing the set away IoT tremendous data using logical contraptions like HadoopMapReduce or Spark .

4. Creating the reports of dismembered data.

\section{IOT ARCHITECTURE}

There is no single agreement on engineering for IoT, which is concurred generally. Various models have been proposed by various analysts. Three-and Five-Layer Architectures.

The most fundamental engineering is a three-layer design as appeared in Figure It was presented in the beginning periods of research in this territory. It has three layers, specifically, the perception, network, and application layers.

(i) The perception layer is the physical layer, which has sensors for detecting and assembling data about nature. It detects some physical parameters or then again distinguishes other brilliant items in the earth.

(ii) The network layer is in charge of interfacing with other savvy things, arrange gadgets, and servers. Its highlights are likewise utilized for transmitting and preparing sensor information.

(iii) The application layer is in charge of conveying application explicit administrations to the client. It characterizes different applications in which the Internet of Things can be conveyed, for instance, keen homes, brilliant urban communities, and keen wellbeing.

The three-layer engineering characterizes the fundamental thought of the Internet of Things, however it isn't adequate for research on IoT in light of the fact that examination frequently centers around better parts of the Internet of Things. That is the reason, we have a lot progressively layered structures proposed in the writing. One is the fivelayer engineering, which furthermore incorporates the handling furthermore, business layers. The five layers are observation, transport, preparing, application, and business layers. The job of the discernment and application layers is equivalent to the engineering with three layers. We plot the capacity of the staying three layers.

(i) The transport layer moves the sensor information from the recognition layer to the preparing layer and bad habit versa through systems for example remote 3G, LAN, Bluetooth RFID, and NFC.

(ii) The processing layer is otherwise called the middleware layer. It stores, breaks down, and forms tremendous sums of information that originates from the vehicle layer. It can oversee and give a various arrangement of administrations to the lower layers It utilizes numerous advances for example databases distributed computing and enormous information preparing modules.

(iii) The business layer deals with the entire IoT framework, counting applications, business and benefit models, what's more, clients' protection. The business layer is out of the extent of this paper.

Another design proposed by Ning and Wang isroused by the layers of preparing in the human mind. It is roused by the knowledge and capacity of people to think, feel, recall, decide, and respond to the physical condition. It is 
established of three sections. First is the human cerebrum, which is practically equivalent to the handling and datamanagement unit or the server farm. Second is the spinal rope, which is practically equivalent to the appropriated system of information preparing hubs and savvy doors. Third is the system of nerves, which relates to the systems administration segments furthermore, sensors.

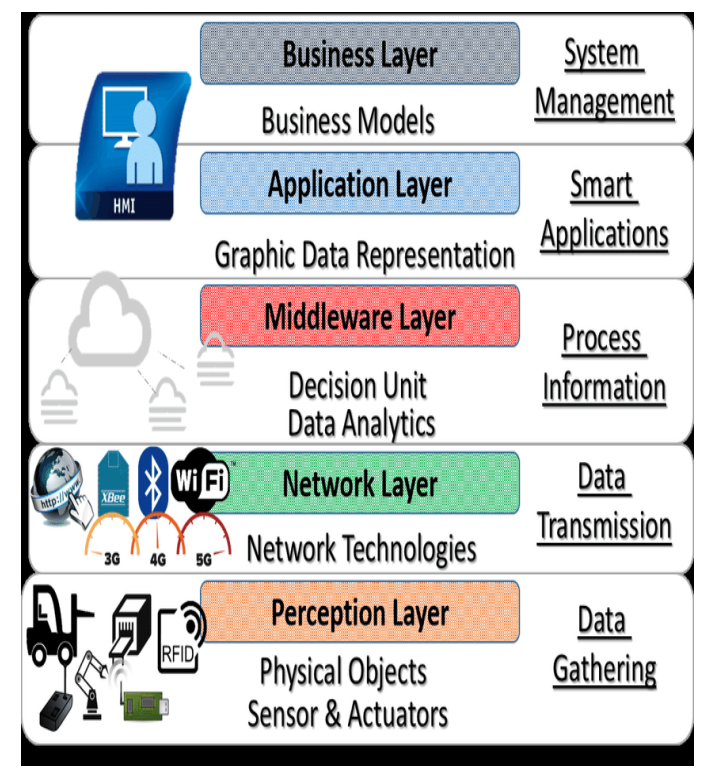

FIGURE 3: IOT ARCHITECTURE

\section{IMPORTANCE OF BIG DATA IN IOT}

IoT is associated system of heterogeneous devices that are equipped for information preparing, information stockpiling and rapid of the Internet which delivers an immense measure of information. Volume, Variety, Velocity and Veracity are the key highlights of enormous information. IoT system is delivering colossal measure of unstructured huge information which will be of no utilization if there is no technique to break down it. Huge information examination comprises of three fundamental advances: stockpiling, handling and result precision. Customarily, the capacity of information is done through Extract, Load and Transform (ELT) method. Attractive, Agile, Deep (MAD) investigationT areT utilizedT in T theseT systems T because T of T whichT aT reasonableT refinement $\mathrm{T}$ has $\mathrm{T}$ been $\mathrm{T}$ made $\mathrm{T}$ between $\mathrm{T}$ information $\mathrm{T}$ stockpiling $\mathrm{T}$ andT information $\mathrm{T}$ the $\mathrm{T}$ executivesT that $\mathrm{T}$ outcomesT inT effectiveT informationT handling.T BecauseT of T MADT investigation, $T$ itT isn'tT justT conceivableT toT includeT newT deviceT intoT theT databaseT ofT IoTT throughT straightforwardT administration $\mathrm{T}$ frameworkT update $\mathrm{T}$ yet $\mathrm{T}$ inT addition $\mathrm{T}$ itsT capacityT of T handlingT informationT at $\mathrm{T}$ fast $\mathrm{T}$ additionally $\mathrm{T}$ makes $\mathrm{T}$ it $\mathrm{T}$ appropriate $\mathrm{T}$ for $\mathrm{T}$ enormous $\mathrm{T}$ IoTT organize.T TheT inconceivability $\mathrm{T}$ of $\mathrm{T}$ enormousT information $\mathrm{T}$ is $\mathrm{T}$ dealt $\mathrm{T}$ with $\mathrm{T}$ throughT different $\mathrm{T}$ parallelT handlingT systemsT likeT MPI,T MapReduceT andT GeneralT PurposeT GPU,T whileT theT preparingT velocityT isT expandedT byT utilizingT filesT forT informationalT collections. $\mathrm{T}$ InT any $\mathrm{T}$ case, $\mathrm{T}$ theseT parallelT handling $\mathrm{T}$ and $\mathrm{T}$ list $\mathrm{T}$ procedures $\mathrm{T}$ are $\mathrm{T}$ utilizedT uniquelyT forT unifiedT enormousT informationT framework.T SoT asT toT utilizeT theseT strategiesT forT circulated IoT arrange a few adjustments are required.
Parallel preparing calculation is utilized in Hadoop, which handles enormous information by further partitioning the informational collections into many sub-informational collections with the goal that its handling should be possible on various devices. Examination of enormous information in IoT should be possible by Hadoop which gives nearby capacity and calculation intensity of numerous processors to these sub sets. In this manner, tremendous measure of information can be handled by commonly sharing assets between neighborhood IoT devices.

\section{IOT APPLICATIONS}

\section{A. Transportation}

The IoT can assume the significant job in coordination of interchanges, control, and data handling crosswise over different transportation. Utilization of the IoT reaches out to all parts of transportation frameworks (for example the vehicle and the driver or client). Dynamic association between these segments of a vehicle framework empowers entomb and intra vehicular correspondence, savvy traffic control, shrewd leaving, electronic, calculated and armada the executives, vehicle control, and wellbeing and street help . Current cars are furnished with sensors which are associated with the web through control frameworks. A portion of the sensors utilized in autos with their positions are given in fig. IoT assumes significant job in street wellbeing frameworks. For example, crash recognition, path change cautioning, traffic sign control, insightful traffic planning as in fig.

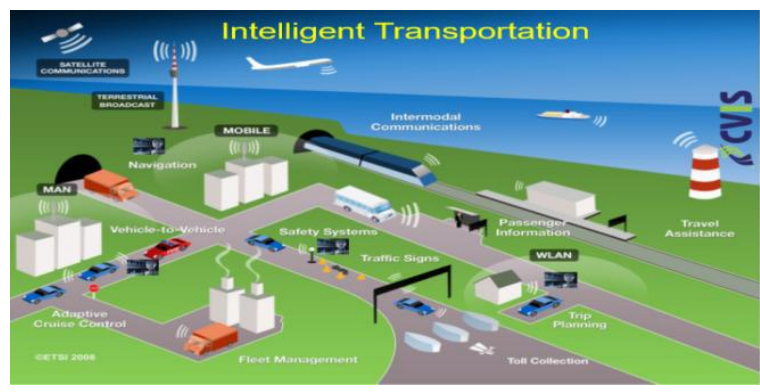

Figure 4: Application of IotIn Transportation

\section{B. Natural Monitoring}

The Environmental checking utilizations of the IoT commonly use sensors to aid ecological security by observing the air situations.like observing the developments of natural life and their living spaces. The physical devices associated with the Internet which are utilized as notice frameworks can likewise be utilized by crisis administrations to give increasingly powerful guide.

\section{Infrastructure Management}

Checking and control tasks of country foundations like scaffolds, railroad track. It is a key utilization of the IoT. The IoT framework can be utilized for observing any occasions or changes in auxiliary conditions that can bargain security and increment chance. It can likewise be utilized for planning fix and support exercises in a proficient way, by organizing errands between various specialist co-ops and clients of these offices. IoTdevices can likewise be utilized to control basic foundation like scaffolds to give access to ships. Utilization of IoTdevices for observing and working 
framework is probably going to improve the board and crisis reaction coordination, and nature of administration, up-times and diminish expenses of activity in all foundation related territories.

\section{Manfacturing}

The IoT empowers the fast assembling of new items and genuine - time enhancement of assembling creation and supply by utilizing organizing hardware, sensors and control frameworks together.

IoT helps in computerized control frameworks to mechanize process, to upgrade the plant wellbeing and security are interlinked with the IoT. Estimations, robotized controls, plant enhancement, wellbeing and security the executives, and different capacities are given by huge number of arranged sensors. National science establishment built up an industry/University agreeable Research focus on canny support systems(IMS). The vision is to accomplish close to zero breakdown utilizing IoT-based assembling.In future we can see the e-producing plants and e-upkeep exercises.

\section{E. Restorative and medicinal services}

IoT devices can be utilized to empower remote wellbeing checking and crisis warning frameworks. A few emergency clinics have started executing savvy beds that can recognize when they are involved and when the patient is endeavoring to get up .

\section{F. Home Automation}

Home computerization is the private augmentation of structure mechanization. It includes the control and robotization of lighting, warming, ventilation, cooling (HVAC), and security, just as home machines, for example, washer/dryers, stoves or fridges/coolers. They use Wi-Fi for remote checking and are a piece of the Internet of things.

\section{G. Media, Entertainment}

Application of IoT in media causes to move information through cloud starting with one spot then onto the next spot, IoT gives great correspondence between individuals through exchange the media to each other. I. Horticulture By form the farming apparatus into savvy devices causes control the water siphons and sprayers are controlled anyplace.

\section{H. Security}

In present day lives there is a dread about hoodlums, by utilizing IoT in home security devices, the security device is worked by a specific indicate.

A significant block in the wide joining of IoT in associations lies in its security. A few difficulties, for example, the constaant Dyn snare, underscore the centrality of having secure IoTdevices, stages, and applications which generally can affect veritable fiascoes, for example, the beneficial execution of

\section{SECURITY CHALLENGES}

a huge DDOS assault. These ambushes can affect precarious impact the relationship of different basic undertakings, undermine national security, and even obviously or in a backhanded way sway human lives. Security is likewise not the fundamental point in the current IoT trades is still, in a manner of speaking, treated as an obligatory yet associate subject. Such rejection can be credited to the nonattendance of various leveled techniques and the ambiguities in government laws. To guarantee an astonishing execution of IoT, lighting up these security issues must be given need in the IoT region. These issues require explicit blueprints similarly as the sensible endorsement of strategies and standards. The perspectives on all assistants in IoT should additionally be considered.

\section{DATA MANAGEMENT ISSUES}

With the exponential enlargement in the proportion of IoTdevices, structures, and techniques, new procedures, for instance, Data Lakes, have move to administer monster data Information Lakes stores dealt with and unstructured information with no pre-imagined thought of how these information will be utilized some time later. This system does not have any significant bearing to plan mapping or request vernaculars and can store any data without imprisonments. Information Lakes presents couple of issues.Utilizing Data Lakes may prompt lost spryness, which is particularly valid for enormous associations that expect to utilize a huge pool of information for brisk examination and basic leadership yet are unfit to do as such productively on the grounds that they should experience a few stages before separating something significant from the information. These associations should rather make a reasonable qualification between those information that can be utilized for basic leadership in close continuous and those information that can be utilized to determine business methodologies.

\section{CONCLUSION}

This paper essentially centers on the job of huge information in IoT\& Big Data. IoT interfaces with huge information when voluminous measures of information should have been prepared, changed, and examined in high recurrence. Such colossal measure of information should be prepared productively. IoT system is delivering colossal measure of unstructured huge information which will be of no utilization if there is no technique to break down it.In this paper we have discuss about the benefits of big data in IOT. And also describe architecture and various applications of IOT.

\section{REFERENCES}

1. Gauer, A.: Smart city Architecture and its applications based on IoT, Procedia computer science, (2015), Vol.52, pp.1089-1094.

2. Saranya C. M., Nitha K. P., Analysis of Security methodsT inT InternetT of T Things. T InternationalT JournalT onT Recent $T$ andT InnovationT TrendsT inT ComputingT andT Communication, T VolumeT 3,T IssueT 4;T AprilT 2015.

3. SapandeepKaur,T IkvinderpalT Singh.T AT SurveyT ReportT onT InternetT of T ThingsT Applications.T InternationalT JournalT of T ComputerT ScienceT TrendsT andT TechnologyT VolumeT 4,T IssueT 2,T MarT -T AprT 2016. 
4. T F.T J.T RigginsT andT S.T F.T Wamba,T "ResearchT directionsT onT theT adoption, $\mathrm{T}$ usage, $\mathrm{T}$ andT impact $\mathrm{T}$ of $\mathrm{T}$ theT internet $\mathrm{T}$ of T thingsT throughT theT useT ofT bigT dataT analytics," T inT ProceedingsT of T 48thT Hawaii International Conference on System Sciences (HICSS'15). IEEE, 2015, pp. 1531-1540.

5. M. R. Bashir and A. Q. Gill, "Towards an iot big data analytics framework: Smart buildings systems," in High Performance Computing and Communications; IEEE 14th International Conference on Smart City; IEEE 2nd International Conference on Data Science and Systems (HPCC/SmartCity/DSS), 2016 IEEE 18th International Conference on. IEEE, 2016, pp. 1325-1332

6. M. K.Kakhani, S. Kakhani and S. R.Biradar, Research issues in big data analytics, International Journal of Application or Innovation in Engineering \& Management, 2(8) (2015), pp.228-232.

7. Chienwattanasook, K., Wattanapongphasuk, W., Prianto, A., \& Jermsittiparsert, K. 2019. "Corporate Entrepreneurship and Business Performance of Logistic Companies in Indonesia." Industrial Engineering \& Management Systems 18 (3): 538-547.

8. Dawabsheh, M., Hussein, A., \& Jermsittiparsert, K. 2019. "The Triangular Relationship between TQM, Organizational Excellence and Organizational Performance: A Case of Arab American University Palestine.” Management Science Letters 9 (6): 921-932.

9. Jermsittiparsert, K., Siam, M., Issa, M., Ahmed, U., \& Pahi, M. 2019. "Do Consumers Expect Companies to Be Socially Responsible? The Impact of Corporate Social Responsibility on Buying Behavior.' Uncertain Supply Chain Management 7 (4): 741-752.

10. Syazali, M., Putra, F., Rinaldi, A., Utami, L., Widayanti, Umam, R. \& Jermsittiparsert, K. 2019. "Partial Correlation Analysis Using Multiple Linear Regression: Impact on Business Environment of Digital Marketing Interest in the Era of Industrial Revolution 4.0." Management Science Letters 9 (11): 1875-1886.

11. Sae-Lim, P. \& Jermsittiparsert, K. 2019. "Is the Fourth Industrial Revolution a Panacea? Risks toward the Fourth Industrial Revolution: Evidence in the Thai Economy." International Journal of Innovation, Creativity and Change 5 (2): 732-752.

12. Chatchawanchanchanakij, P., Arpornpisal, C., \& Jermsittiparsert, K. 2019. "The Role of Corporate Governance in Creating a Capable Supply Chain: A Case of Indonesian Tin Industry." International Journal of Supply Chain Management 8 (3): 854-864.

13. Hartinah, S., Suharso, P., Umam, R., Syazali, M., Lestari, B., Roslina R., \& Jermsittiparsert, K. 2020. "Teacher's Performance Management: The Role of Principal's Leadership, Work Environment and Motivation in Tegal City, Indonesia." Management Science Letters 10 (1): 235-246.

14. Haseeb, M., Hussain, H., Slusarczyk, B., \& Jermsittiparsert, K. 2019. "Industry 4.0: A Solution towards Technology Challenges of Sustainable Business Performance.” Social Sciences 8 (5): 184.

15. Haseeb, M., Hussain, H., Kot, S., Androniceanu, A., \& Jermsittiparsert, K. 2019. "Role of Social and Technological Challenges in Achieving a Sustainable Competitive Advantage and Sustainable Business Performance." Sustainability 11 (14): 3811

16. Haseeb, M., Kot, S., Hussain, H., \& Jermsittiparsert, K. 2019 "Impact of Economic Growth, Environmental Pollution, and Energy Consumption on Health Expenditure and R and D Expenditure of ASEAN Countries.” Energies 12 (19): 3598.

17. Huda, S., Tsani, I., Syazali, M., Umam, R., \& Jermsittiparsert, K 2020. "The Management of Educational System Using Three Law Auguste Comte: A Case of Islamic Schools." Management Science Letters 10 (3) (In press), DOI: 10.5267/j.msl.2019.9.018.

18. Usak, M., Kubiatko, M., Shabbir, M., Dudnik, O., Jermsittiparsert, K., \& Rajabion, L. 2019. "Health Care Service Delivery Based on the Internet of Things: A Systematic and Comprehensive Study." International Journal of Communication Systems 32 (14): e4179.

19. Jermsittiparsert, K., Ambarita, D., Mihardjo, L., \& Ghani, E. 2019. "Risk-Return through Financial Ratios as Determinants of Stock Price: A Study from ASEAN Region." Journal of Security and Sustainability Issues 9 (1): 199-210.

20. Maseleno, A., Hardaker, G., Sabani, N., \& Suhaili, N. (2016). Data on multicultural education and diagnostic information profiling: Culture, learning styles and creativity. Data in brief, 9, 1048.

21. Maseleno, A., Huda, M., Jasmi, K. A., Basiron, B., Mustari, I., Don, A G., \& bin Ahmad, R. (2019). Hau-Kashyap approach for student's level of expertise. Egyptian Informatics Journal, 20(1), 27-32.

22. Maseleno, A., Huda, M., Siregar, M., Ahmad, R., Hehsan, A., Haron, Z., ... \& Jasmi, K. A. (2017). Combining the previous measure of evidence to educational entrance examination. Journal of Artificial Intelligence, 10(3), 85-90.

23. Thabhiranrak, T. \& Jermsittiparsert, K. 2019. "Towards Sustainable Functioning of Organization: Women Empowernment and Corporate
Management Culture." Journal of Security and Sustainability Issues 9 (1): 321-332.

24. Chienwattanasook, K. \& Jermsittiparsert, K. 2019. "Impact of Entrepreneur Education on Entrepreneurial Self-Employment: A Case Study from Thailand.” Polish Journal of Management Studies 19 (1): 106-116.

25. Jermsittiparsert, K., Sutduean, J., Sriyakul, T., \& Khumboon, R. 2019. "The Role of Customer Responsiveness in Improving the External Performance of an Agile Supply Chain." Polish Journal of Management Studies 19 (2): 206-217.

26. Jermsittiparsert, K., Sutduean, J., \& Sriyakul, T. 2019. "Effect of Service Innovation and Market Intelligence on Supply Chain Performance in Indonesian Fishing Industry." Industrial Engineering \& Management Systems 18 (3): 408-417.

27. Jermsittiparsert, K., Namdej, P., \& Somjai, S. 2019. "Green Supply Chain Practices and Sustainable Performance: Moderating Role of Total Quality Management Practices in Electronic Industry of Thailand." International Journal of Supply Chain Management 8 (3) 33-46.

28. Somjai, S. \& Jermsittiparsert, K. 2019. "The Trade-off between Cost and Environmental Performance in the Presence of Sustainable Supply Chain." International Journal of Supply Chain Management 8 (4): 237-247.

29. Jermsittiparsert, K. \& Sawasdee, A. 2012. "Formal Education for Non-Thai or Undocumented Person in Thailand amidst the Challenge of Nationalism and Transnationalism: A Case Study of Wa Sirimongkhol School, Samut Sakhon Province." Kasetsart Journal Social Sciences 33 (2): 203-213.

30. A. Gandomi and M. Haider, Beyond the hype: Big data concepts, methods, and analytics, International Journal of Information Management, 35(2) (2015), pp.137-144.

31. Harshawardhan S. Bhosale, Prof. Devendra P. Gadekar,T "AT ReviewT PaperT onT BigT DataT andT Hadoop",InternationalT JournalT ofT ScientificT andT ResearchT Publications, T VolumeT 4,T IssueT 10,T ISSN:T 2250-3153,T OctoberT 2014

32. T ZanT Mo,T YanfeiT Li,'T ResearchT ofT BigT DataT BasedT onT theT ViewsT ofT TechnologyT andT Application",AmericanT JournalT ofT IndustrialT andT BusinessT Management,T 192-197,T 2015.

33. T S.T JustinT Samuel, Koundinya RVP, KothaSashidhar and C.R. Bharathi," A Survey on Big Data and Its Research Challenges", ARPN Journal of Engineering and Applied Sciences, VOL. 10, NO. 8,ISSN:1819-6608, May2015.

34. BijeshDhyani, AnuragBhartwal,"Big Data Analytics using Hadoop", International Journal of Computer Applications (0975 - 8887) ,Volume 108 - No 12, December 2014 